\title{
Scanning electron microscopic examination of customized titanium abutments before and after different cleaning procedures
}

Klews, C; Nentwig, GH

Submitted by Christian Klews, Department of Oral Surgery and Implantology, Dental School (Carolinum), Johann Wolfgang Goethe-University Frankfurt, Frankfurt am Main, Germany.

\section{Abstract}

Aim: The aim of this study was to assess the degree of contamination on customized titanium abutments after processing in the dental laboratory. In order to figure out the highest cleaning efficiency, abutments were examined before and after different cleaning and disinfection procedures.

\section{Methods and Materials}

Forty abutments of the type Ankylos Balance anterior small 3.0/0 (Dentsply Implants) underwent a standardized laboratory procedure and were afterwards randomly divided into three groups: group A (10 abutments), group B (15 abutments) and group C (15 abutments). Group A was cleaned solely with a disinfecting solution consisting of MD 520, chlorhexidine and water. Group B was cleaned in addition to the disinfecting solution used in group $A$ with an ultrasonic cleaner. Lastly, the ultrasonic cleaner and an acetone-containing solution were utilized for group $\mathrm{C}$. Contamination was measured before and after the cleaning procedures by electron microscopy (SEM Hitachi $S 4500$ ). The percentage share of the contaminated area was calculated for each group and cleaning efficiency was determined by using the Wilcoxon-Matched-Pairs-Test. The Wilcoxon-Mann-Whitney-Test was applied to compare the cleaning efficiency between the different groups. Statistical significance was obtained when $p \leq 0.5$.

\section{Results}

The analysis of group $A$, which showed an average percentage share of contamination of $30.5 \%$ before cleaning and of $27.5 \%$ after cleaning, failed to reveal any statistical significant cleaning efficiency. The use of

ultrasonic cleaning in group $\mathrm{B}$, with an average percentage share of contamination of $26.3 \%$ before cleaning and of $5.3 \%$ after cleaning, achieved statistical significance with a $p$-value of $p=0.000061$. Nevertheless, the combination of an ultrasonic cleaner with an acetone-containing solution led to the highest cleaning efficiency in group $\mathrm{C}$, which had an average percentage share of contamination of $31.7 \%$ before cleaning and of $1.25 \%$ after cleaning $(p=0.000061)$.

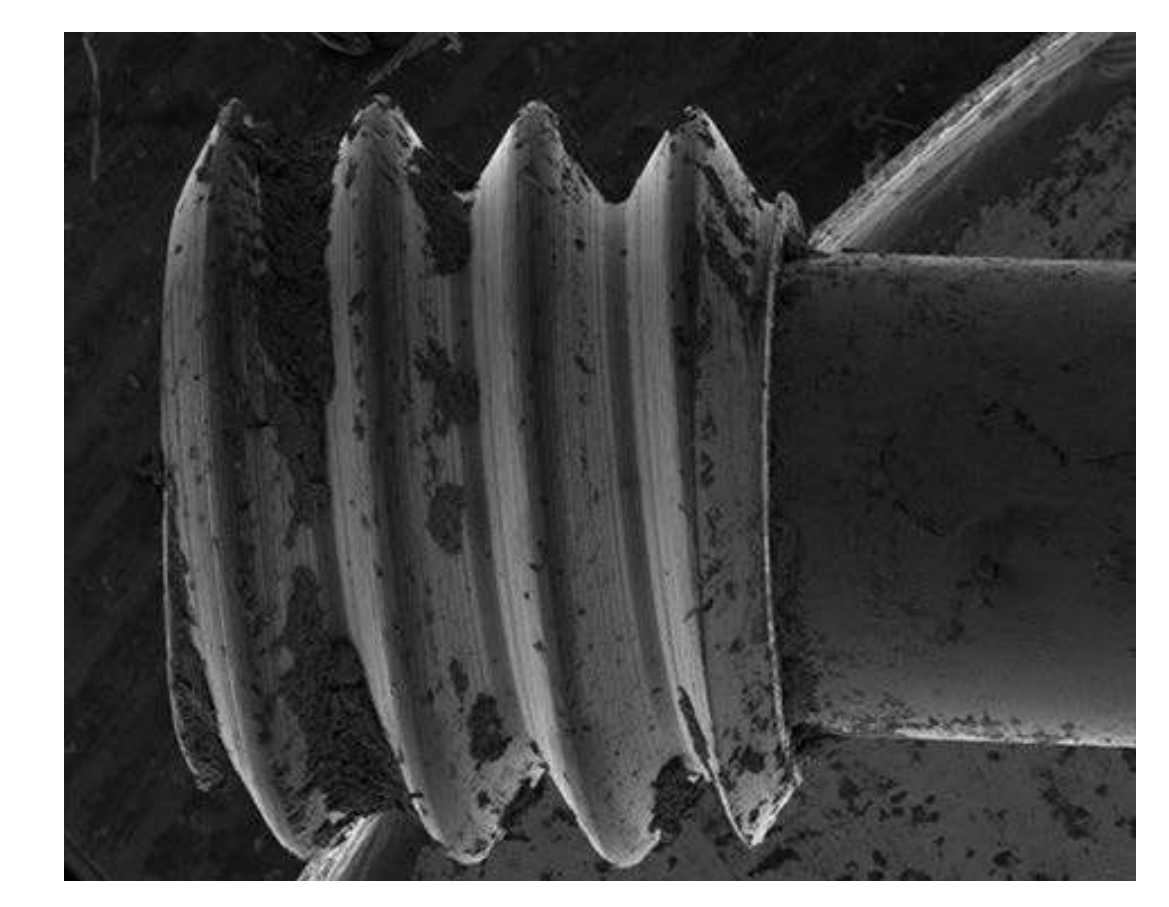

III 1. Screw thread of a customized titanium abutment after cleaning with steam, before cleaning with a desinfecting solution

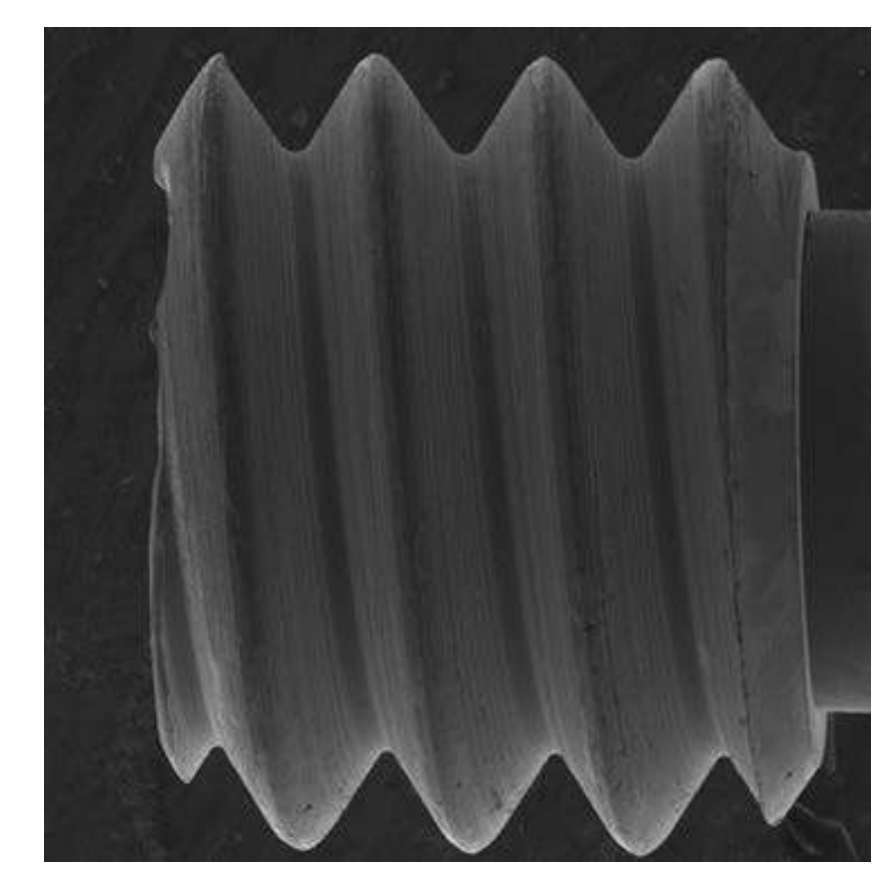

III 2. Screw thread of customized and an acetone-containing solution

\begin{tabular}{|c|c|c|}
\hline $\begin{array}{l}\text { Group A (10 abutments): } \\
\text { Contamination (\%) } \\
\text { before cleaning with } \\
\text { different mediums (MD } \\
\text { 520, CHX, H2O) }\end{array}$ & $\begin{array}{l}\text { Contamination (\%) } \\
\text { after cleaning }\end{array}$ & $\begin{array}{l}\text { Difference } \\
\text { (\%) }\end{array}$ \\
\hline \multicolumn{3}{|l|}{ MD 520} \\
\hline 25 & 18 & 7 \\
\hline 30 & 24 & 6 \\
\hline 27 & 22 & 5 \\
\hline \multicolumn{3}{|l|}{ CHX } \\
\hline 45 & 43 & 2 \\
\hline 24 & 21 & 3 \\
\hline 32 & 30 & 2 \\
\hline \multicolumn{3}{|l|}{$\mathrm{H} 2 \mathrm{O}$} \\
\hline 35 & 35 & 0 \\
\hline 30 & 29 & 1 \\
\hline $\begin{array}{l}\text { Group C (15 abutments): } \\
\text { Contamination (\%) before } \\
\text { ultrasonic cleaning and an } \\
\text { acetone-containing solution }\end{array}$ & $\begin{array}{l}\text { Contamination (\%) } \\
\text { after ultrasonic } \\
\text { cleaning and an } \\
\text { acetone-containing } \\
\text { solution }\end{array}$ & $\begin{array}{l}\text { Difference } \\
\text { (\%) }\end{array}$ \\
\hline 19 & 1,5 & 17,5 \\
\hline 16 & 1 & 15 \\
\hline 32 & 3 & 29 \\
\hline 19 & 0,2 & 18,8 \\
\hline 37 & 1,7 & 35,5 \\
\hline 53 & 1,8 & 51,2 \\
\hline 44 & 0,6 & 43,3 \\
\hline 33 & 1,8 & 31,2 \\
\hline 28 & 1 & 27 \\
\hline 25 & 0,7 & 24,3 \\
\hline 31 & 1,8 & 29,3 \\
\hline 36 & 0,8 & 35,2 \\
\hline 37 & 1 & 36 \\
\hline 33 & 0,9 & 32,1 \\
\hline 33 & 1 & 32 \\
\hline
\end{tabular}

\section{Conclusions}

This study confirmed the presence of contamination after mechanical processing of customized titanium abutments. The analysis of different cleaning procedures showed that the exclusive employment of cleaning solutions without an ultrasonic cleaner has the lowest cleaning efficiency. Using an ultrasonic cleaner in combination with a disinfecting agent or solution can achieve sufficient cleaning efficiency in contaminated customized abutments.

\section{References}

Canullo, L.; Penarrocha-Oltra, D.; Marchionni, S.; Bagan, L.; Penarrocha-Diago, M-A; Micarelli, C. (2014):

to titanum abutments after differentcleaning proc ter different cleaning procedures: preliminary results of a randomized clinical trial.

In: Medicina oral, patologia oral y cirugia bucal 19 (2), e177-83. titanium screw after ultrasonic cleaning
Canullo, L., Micarelli, C., Lembo-Fazio, L., lannello, G., Clementini, M. (2014): Microscopical and microbiologic characterization of customized titanium abutments after different cleaning procedures.

In: Clinical oral implants research 25 (3), S. 328-336. DOI: 10.1111/clr.12089

Jatzwauk, L., Schone, H., Pietsch, H. (2001)

How to improve instrument disinfection by ultrasound.

In: The Journal of hospital infection 48 Suppl A, S80-3. 